\title{
Fracture Dislocations of the Coccyx: A Case Series and Literature Review
}

\section{Kamal Hamoud MD, FRCS (Eng), MCh (Orth) ${ }^{1,2,3}$ and Janan Abbas PhD ${ }^{3}$}

${ }^{1}$ Faculty of Medicine in the Galilee, Bar-llan University, Henrietta Szold st. 8, POB 1589, Safed, Israel

${ }^{2}$ Department of Orthopaedic Surgery, The Baruch Padeh Poriya Medical Center, Tiberias, Lower Galilee, Israel,

${ }^{3}$ Department of Physiotherapy, Zefat Academic College, Zefat, Israel

\begin{abstract}
Study design: A case report and literature review.

Objective: To present a rare case series of dislocation of the mid-coccygeal and sacro-coccygeal joints in a young adult and a baby, who were treated conservatively.

Summary of background data: Dislocations of the mid-coccygeal or the sacro-coccygeal joints are infrequent injuries and are rarely reported. The treatment for these disorders is usually conservative.

Methods: Detailed description of the posterior dislocation of the mid-coccygeal joint in a 19-year-old patient and a complete anterior dislocation (Salter-Harris type I) of the sacro-coccygeal joint in a 2 year and 8 months baby and management of both cases are presented, with review of the relevant literature.

Results: A conservative treatment was performed in both cases. Clinical and radiological results at sixteen months after the injury in the first case, and five months in the second, revealed excellent results, with good healing of the dislocation and in normal alignment.

Conclusion: Fracture dislocation of the mid-coccygeal and sacro-coccygeal joints in the young adults and pediatric population could be treated conservatively, as the potential of healing and remodelling is great. Closed reduction should not be attempted.
\end{abstract}

Keywords: Sacro-coccygeal; Dislocation; Coccyx; Pediatric; Closed reduction

\section{Introduction}

Fracture dislocation of the coccyx in the pediatric and adult populations is a rare injury and infrequently reported. Furthermore, fracture dislocations of the sacro-coccygeal joint or dislocation of the mid-coccygeal joint in this group of patients are even rarer. Different treatment options are described for these injuries. Closed reduction under general anaesthesia was unsuccessfully tried; therefore, conservative treatment was continued $[1,2]$.

In this study, we present two cases of dislocation of the coccyx. Both were treated conservatively. The first case is of a 19-year-old man who was involved in a motorcycle road traffic accident and suffered from a posterior dislocation of the second coccygeal vertebra. Excellent healing and remodelling of the dislocation were demonstrated at sixteen months after the accident. The second is of a girl aged 2 years and 4 months, who sustained a complete anterior dislocation of the coccyx, following a fall on the edge of a step. Five months later, good healing of the dislocation in normal alignment was evident in the check X-ray.
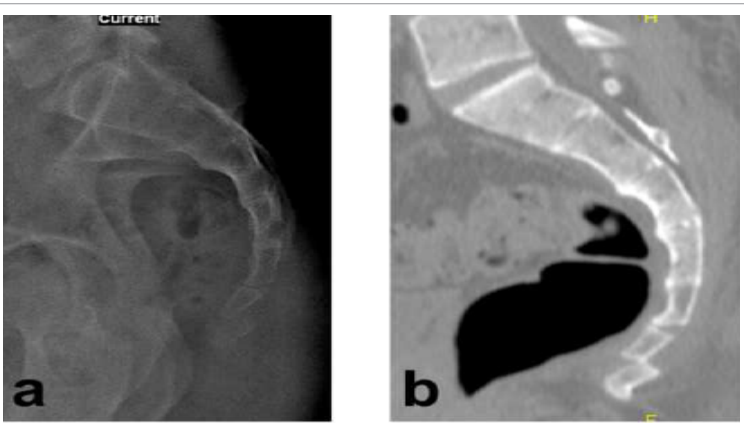

Figure 1: Lateral radiograph (a) and sagittal reconstruction computed tomographic image (b) of the sacrum and coccyx showing complete posterior dislocation of the joint between the 1 st and 2 nd coccygeal vertebrae.
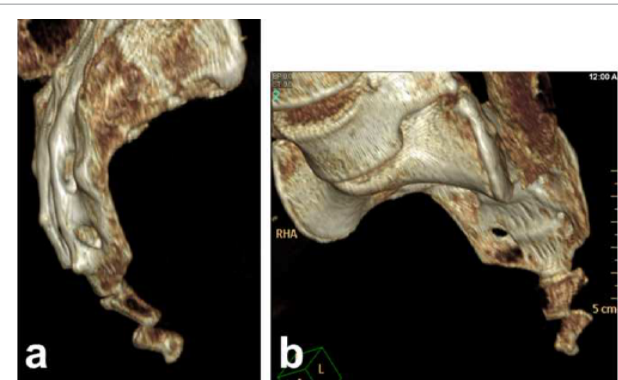

Figure 2: Postero-lateral (a) and antero-lateral (b) 3D reconstruction views, demonstrating the posterior dislocation of the mid-joint of the coccyx.

\section{Case Reports}

\section{Case 1}

A 19-year-old motorcyclist was admitted to our center, following a road traffic accident, when his motorcycle slipped on a wet road. He was thrown away, landing on his tailbone. On arrival at the emergency room, he complained of severe pain at the area of the coccyx, upper and lower back. On examination, there was a localized tenderness over the coccyx and the thoraco-lumbar junction. X-rays and computed tomography of the spine showed complete posterior dislocation of the joint between the $1^{\text {st }}$ and $2^{\text {nd }}$ coccygeal vertebrae (Figures 1 and 2), and

*Corresponding author: Kamal Hamoud, Galilee, Bar-llan University, Ramat Gan, Israel, Tel: 972-52 4060008; E-mail: k_hamoud@yahoo.com

Received June 27, 2017; Accepted August 22, 2017; Published August 27, 2017

Citation: Hamoud K, Abbas J (2017) Fracture Dislocations of the Coccyx: A Case Series and Literature Review. J Clin Case Rep 7: 1005. doi: 10.4172/21657920.10001005

Copyright: (c) 2017 Hamoud K, et al. This is an open-access article distributed under the terms of the Creative Commons Attribution License, which permits unrestricted use, distribution, and reproduction in any medium, provided the original author and source are credited. 


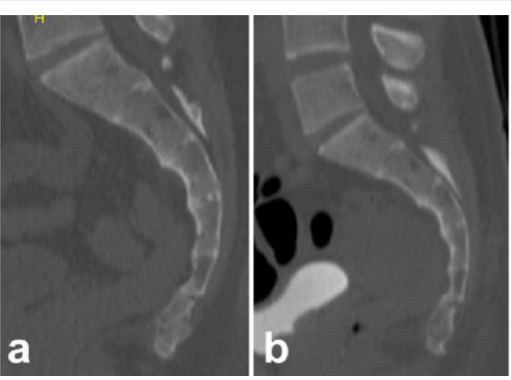

Figure 3: Sagittal reconstruction computed tomographic image of the sacrum and coccyx, performed at ten months (a) and sixteen months (b) after the injury, showing excellent healing of the dislocation, with anatomical remodeling.

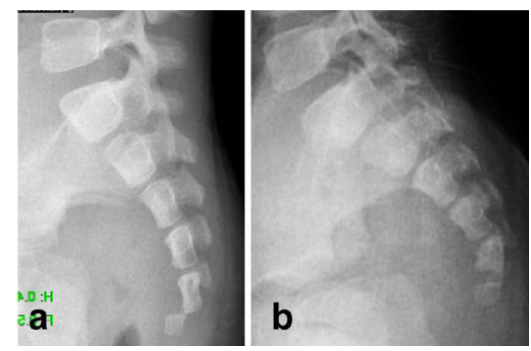

Figure 4: Lateral radiograph of the sacrum and coccyx obtained two days after the injury (a), showing complete anterior dislocation of the sacro-coccygeal joint (Salter-Harris type I), and five months later (b), demonstrating excellent healing and modeling of the dislocation at the sacro-coccygeal junction.

minimal compression fractures of the upper end-plates of D10, D11 and L3 vertebrae. He was admitted for observation and conservative treatment, including rest for few days, back brace and analgesic drugs as needed. Reduction of the coccygeal dislocation was not attempted. Six weeks after the accident, most of his symptoms resolved. Later, he was lost to follow up. However, according to his medical records, a computed tomography due to abdominal pain was performed on him ten months after the injury, and it showed good healing of the dislocation and partial union in good alignment between the dislocated coccygeal vertebrae (Figure 3a). Sixteen months after the injury, he underwent another computed tomography due to renal colic. This demonstrated excellent remodelling and healing of the dislocation of the coccyx in normal alignment (Figure 3b).

\section{Case 2}

A 2 years and 4 months baby girl was admitted to our emergency room after she slipped over the stairs two days prior to her admission and fell on the edge of the step, hitting her tailbone. She was complaining of pain and discomfort while sitting. On examination, there was mild swelling and tenderness at the end of the sacrum. Lateral radiograph of the sacrum and coccyx demonstrated complete anterior dislocation of the first coccygeal vertebra (Figure 4a). Conservative treatment was recommended and she was discharged. Five months after the injury she was free of symptoms. Check radiograph showed good healing of the dislocation and normal alignment of the sacro-coccygeal junction (Figure 4b).

\section{Discussion}

Isolated fracture dislocations of the sacrum in children are rarely reported and appear to be more common than previously realized [1]. However, Sacro-coccygeal fracture-dislocation and dislocations of the mid-coccygeal joints in the pediatric and young adult populations are extremely rare injuries.
In this study, we report two interesting and rare cases. The first case is of a young adult, who sustained a dislocation at the level of the $1^{\text {st }}$ and $2^{\text {nd }}$ coccygeal vertebrae, which was treated conservatively, with excellent remodelling. To the best of our knowledge, this is the first case to be reported with such an injury.

The second case is of a young baby with a complete anterior SalterHarris type I fracture dislocation of the coccygeal bone. Excellent healing and modelling was already obvious at 5 months after the injury. Probably it is the first case to be reported with such an injury in this age.

In a previous report $[2,3]$, we have described a similar injury of a complete anterior fracture dislocation of the coccygeal bone in a 12-year-old boy. Attempted closed reduction under general anesthesia failed, therefore conservative treatment was continued, with excellent clinical and radiological outcome. We assume that the periosteum was detached at the site of the dislocation, allowing new bone to be laid, consolidate and remodel eventually to result in normal sacro-coccygeal structure. Periosteal separation has been well reported in different types of injuries in the pediatric population [4-7].

These excellent clinical and radiological results in our series imply that there is no need for reduction trials for these injuries in the growing child, as well as in young adults, as the potential of modelling is great. Closed reduction proved to be unsuccessful in our previous case, the same as have been reported in the literature $[1,2,8]$. Also, this technique was unsuccessful in adults with similar injuries. A "Joystick reduction technique" and percutaneous pinning for an acutely anteriorly dislocated coccyx in a thin 31-year-old woman was described by., $[8,9]$, while Bergkamp reported an anterior dislocation of the coccyx in a 26year old woman, who was treated by open reduction and fixation using vicryl sutures [10]. In both cases, surgery was performed after failure of per rectally closed reduction.

Our review of the English literature revealed only two similar cases of sacro-coccygeal fracture-dislocation in children [1,2]. Additionally, Rijal et al. reported an acute anterior sacro-coccygeal dislocation in a 29-year-old man [8]. In all these cases, attempted reduction has failed and no long-term follow up was reported. On the other hand, we could not find any case of dislocation at the mid-joints of the coccyx in children or adults.

\section{Conclusion}

Fracture dislocations of the sacro-coccygeal joint in the growing child and dislocations of the mid-joints of the coccyx in young adults could be treated conservatively, as the potential of healing and anatomical modelling is great. Closed reduction of these injuries should not probably be attempted, though very tempting, as it will most probably fail.

\section{References}

1. Gutierrez PR, Mas Martinez JJ, Arenas J (1998) Salter-Harris type I fracture of the sacro-coccygeal joint. Pediatr Radiol 28: 734.

2. Raissaki MT, Williamson JB (1999) Fracture dislocation of the sacro-coccygeal joint: MRI evaluation. Pediatr Radiol 29: 642-643.

3. Hamoud K, Abbas J (2015) Fracture dislocation of the sacro-coccygeal joint in a 12-year-old boy. A case report and literature review. Orthop Traumatol Surg Res 101: 871-873.

4. Stuart J, Boyd R, Derbyshire S, Wilson B, Phillips B (1998) Magnetic resonance assessment of inversion ankle injuries in children. Injury 29: 29-30.

5. Close BJ, Strouse PJ (2000) MR of physical fractures of the adolescent knee. Pediatr Radiol 30: 756-762. 
Citation: Hamoud K, Abbas J (2017) Fracture Dislocations of the Coccyx: A Case Series and Literature Review. J Clin Case Rep 7: 1005. doi: 10.4172/2165-7920.10001005

6. Meyers AB, Laor T, Zbojniewicz AM, Anton CG (2012) MRI of radiographically occult ischial apophyseal avulsions. Pediatr Radiol 42: 1357-1363.

7. Gleeson AP, Stuart MJ, Wilson B, Phillips B (1996) Ultrasound assessment and conservative management of inversion injuries of the ankle in children: Plaster of Paris versus Tubigrip. J Bone Joint Surg Br 78: 484-487.

8. Rijal KP, Pradhan RL, Sharma S, Lakhey S, Pandey BK (2004) Acute sacrococcygeal dislocation (anterior type): A case report. Kathmandu Univ Med J (KUMJ) 2: 367-368.

9. Kim WY, Han CW, Kim YH (2004) Joystick reduction and percutaneous pinning for an acutely anteriorly dislocated coccyx: A case report. J Orthop Trauma 18: 388-389.

10. Bergkamp AB, Verhaar JA (1995) Dislocation of the coccyx: A case report. J Bone Joint Surg $\mathrm{Br}$ 77: 831-832. 